\title{
Homens, vítimas e autores de violência: a corrosão do espaço público e a perda da condição humana
}

Rejane Aparecida Alves ${ }^{1}$ Lauriza Maria Nunes Pinto ${ }^{2}$

Andréa Maria Silveira ${ }^{3}$ Graziella Lage Oliveira ${ }^{4}$ Elza Machado de Melo ${ }^{5}$

ALVES, R.A. et al. Men, victims and perpetrators of violence: the corrosion of public space and the loss of the human condition. Interface - Comunic., Saude, Educ., v.16, n.43, p.871-83, out./dez. 2012.

This was a qualitative study conducted in the municipality of Ribeirão das Neves, MG, with the aim of understanding men's involvement in violence. The methodology consisted of focus groups were organized according to sex, age and administrative region of the municipality. There were 30 groups in total, with 231 randomly recruited participants. For the analysis, the hermeneutical-dialectical method was used and, in light of Hannah Arendt's political theory, violence was interpreted as domination that permeates human relationships. Men and women were identified as possible perpetrators and victims of violence, and their involvement was defined in accordance with the inequality of relationships established. The numbers of the violence and explanations centered on biological theories may lead to the premature conclusion that men are more violent than women. The theoretical basis and greater depth of contextualization make it possible to throw light on other aspects of this important issue.

Keywords: Men's health. Violence. Socialization. Masculinity.
Trata-se de estudo qualitativo, realizado no Município de Ribeirão das Neves-MG, com o objetivo de compreender o envolvimento dos homens com a violência. A metodologia consistiu de grupos focais organizados segundo sexo, faixa etária e região administrativa do Município, sendo, ao todo, trinta grupos, com 231 participantes, recrutados aleatoriamente. Para analisar, foi utilizado o método hermenêutico-dialético e, à luz da teoria política de Hannah Arendt, a violência foi interpretada como dominação que perpassa as relações humanas. Homens e mulheres foram identificados como possíveis autores e vítimas de violência, o envolvimento de cada um sendo definido a partir de relações desiguais que estabelecem. Os números da violência, assim como as explicações centradas em teorias biológicas, podem levar à conclusão prematura de que os homens sejam mais violentos do que as mulheres. A fundamentação teórica e a contextualização mais profundas permitem clarear outras faces desse importante problema.

Palavras-chave: Saúde do homem. Violência. Socialização. Masculinidade.
- Elaborado com base em Alves (2011); pesquisa financiada pela Organização PanAmericana de Saúde (OPAS), apoiada pelo Núcleo de Promoção de Saúde e Paz do Departamento de Medicina Preventiva e Social, Faculdade de Medicina, Universidade Federal de Minas Gerais (DMPS/FM/UFMG) e aprovada pelo Comitê de Ética em Pesquisa da UFMG.

${ }^{1}$ Mestranda, Programa de Pós-Graduação em Saúde Pública, UFMG.

Av. Alfredo Balena 190, sala 810, Santa Efigênia. Belo Horizonte, MG, Brasil. 30.130-100 reaalves@yahoo.com.br ${ }^{2-4}$ Núcleo de Promoção de Saúde e Paz DMPS/FM/UFMG ${ }^{5}$ Programa de PósGraduação em Saúde Pública, UFMG. 


\section{Introdução}

Mundialmente, a saúde dos homens apresenta uma situação de desvantagem em relação à das mulheres, evidenciada por maior risco de morte, especialmente, em idades mais precoces (Tong et al., 2011; United Nations, 2010; Gomes, Nascimento, 2006; Laurent et al., 2005; Meryn, Jadad, 2001; World Health Organization, 2000).

Apesar de conhecido, esse problema foi tradicionalmente relegado pelas políticas públicas e, só nas últimas décadas, ganhou o interesse do setor da saúde (Smith, Robertson, 2008; Gomes, Nascimento, 2006; Meryn, Jadad, 2001), quando surgiram iniciativas, em diversos países, reconhecendo os homens como sujeitos do cuidado de saúde e portadores de necessidades e abordagens específicas. No Brasil, foi publicada, em agosto de 2009, a Política Nacional de Atenção Integral à Saúde do Homem (Brasil, 2009a, 2009b). Esse movimento mundial em defesa da saúde do homem sinaliza uma ruptura com a visão parcial que afasta e/ou exclui o homem do papel do cuidado, pautado nas diferenças instituídas pelas construções de gênero (Couto et al., 2010).

Dentre as principais causas de morbimortalidade masculina, destaca-se a violência (Tong et al., 2011; World Health Organization, 2010a, 2000; Brasil, 2009a; Melo et al., 2008; Laurent et al., 2005; Meryn, Jadad, 2001). Segundo a World Health Organization (2010a), das mais de 1,5 milhões mortes anuais por causas violentas (homicídios, acidentes de transporte e suicídios), a maioria é de homens, principalmente na faixa etária de 15 a 29 anos. Além disso, muitos sofrem com graves sequelas não fatais (World Health Organization, 2010a, 2000; Melo et al., 2008). Em 2004, homens morreram, aproximadamente, três vezes mais do que mulheres em consequência de acidentes de transporte e de homicídios, e duas vezes mais devido aos suicídios (World Health Organization, 2010b). Das 468 mil mortes por assassinatos no mundo, em 2010, mais da metade eram homens e jovens (United Nations Office on Drugs and Crime, 2011). Em 2009, no Brasil (Brasil, 2011), a razão das taxas de mortalidade por violência entre homens e mulheres foi de 7:1. A expectativa de vida do Brasil poderia ser superior em dois ou três anos à atual se não fosse o efeito das mortes prematuras de homens por causas violentas (Instituto Brasileiro de Geografia e Estatística 2011). Isso mostra que a violência, assim como outros problemas de saúde, não é igualmente distribuída entre os sexos ou grupos etários (Krug et al., 2002).

Estudos sobre a estreita relação entre os homens e a violência (Carrington et al., 2010; World Health Organization, 2010a, 2000; Brasil, 2009a; Nascimento et al., 2009; Alvim, Souza, 2005; Schraiber et al., 2005) apresentam explicações vinculadas à socialização dos homens, centrada em um hegemônico modelo de masculinidade instituidor de papéis e de posições sociais desiguais entre os gêneros, além de crenças que propiciam o envolvimento destes sujeitos com a violência, como: a soberania masculina, a valentia, a honra, a dominação, a invulnerabilidade e a força. Este modelo naturaliza a violência como um atributo dos homens e como um instrumento de afirmação do "ser homem", e os induz à adoção de práticas de risco à vida e de condutas autoritárias, ambas geradoras de relações humanas violentamente conflituosas.

O desafio imposto pela violência no âmbito da saúde do homem e a necessidade de novos olhares sobre esta questão geraram este estudo, realizado no Município de Ribeirão da Neves-MG, cujo objetivo foi compreender, à luz dos fundamentos teóricos de Hannah Arendt, o envolvimento dos homens com a violência, seja na condição de vítimas ou autores.

Hannah Arendt amplia os horizontes explicativos da violência ao reconhecê-la como um produto da dominação própria das relações humanas desiguais, que trazem como pano de fundo: a instrumentalização do sujeito, a aniquilação da fonte do poder legítimo - as interações humanas em pé de igualdade - e a consequente perda da condição humana. Sendo a dominação o marcador da condição masculina imposto pela socialização do homem, potencializa-se o estreitamento da relação homem-violência. 


\section{Ribeirão das Neves}

Município mineiro integrante da região metropolitana de Belo Horizonte, Ribeirão das Neves contava, em 2010, com uma população de 296.317 habitantes, dos quais, 99\% viviam em área urbana (IBGE, 2011). Desde a década de 1950, este município sofre com o intenso crescimento populacional e a ocupação territorial desordenada, em oposição à capacidade administrativa de oferecer uma infraestrutura local suficiente para atender as demandas da população (Ribeirão das Neves, 2008). O setor econômico oferece poucas alternativas de trabalho, há predomínio de atividades informais (Ribeirão das Neves, 2008), consequentemente, a maior parte da população é de baixa renda e vive com renda média de até dois salários-mínimos (IBGE, 2011). A existência de um complexo penitenciário de seis unidades em seu território, que abrigava, em 2006, 3.383 presos (Ribeirão das Neves, 2008), desestimula o crescimento econômico local, pois desvaloriza os imóveis da região, limita a atração de investimentos, prejudica o comércio e agrava o quadro de explosão demográfica pela migração de parentes dos detentos (Ribeirão das Neves, 2008).

Estas fragilidades configuram um quadro de vulnerabilidade expressa em desempregos, empregos precários, pobreza, misérias e exclusão social, que acirram os conflitos nos contextos da vida humana e favorecem a instauração da violência como o maior problema para o município, com estatísticas que se destacam no Estado de Minas Gerais (Brasil, 2011; Ribeirão das Neves, 2008). As taxas de morte por violência no município estão concentradas na população masculina, com maior impacto na faixa etária de 15 a 29 anos (Brasil, 2011). Desde 2002, os eventos violentos, especialmente os homicídios, ocupam a primeira posição entre as principais causas de morte dos homens (Brasil, 2011). Em 2009, $85 \%$ das mortes violentas foram de homens e geraram taxas seis vezes maiores para os homens em relação às mulheres (Brasil, 2011).

\section{Referencial teórico}

Inspirada pela Teoria Política de Hannah Arendt (2008, 1994), a violência foi definida como a dominação própria de relações humanas marcadas pela ausência do diálogo e pela instrumentalização do sujeito.

Orientada pelos princípios políticos do pensamento greco-romano e em discordância com o pensamento político moderno, essa autora sustenta uma oponente distinção conceitual entre violência e poder, sendo o último definido como fenômeno político, fundado em relações humanas argumentativas, diferentemente do entendimento atual que o identifica com dominação, sinônimo de violência, que se assenta em relações de mando-obediência.

Arendt (2008) reconhece três atividades humanas fundamentais: o labor, o trabalho e a ação. A primeira constitui a condição humana da vida, por garantir a realização das necessidades vitais; a segunda constrói o mundo artificial que confere certa durabilidade à fugacidade do tempo humano, e a ação corresponde à atividade que se desenvolve entre os homens e tem como condição a pluralidade, isto é, nossa condição de iguais e diferentes, todos humanos, mas cada um único e distinto de "qualquer pessoa que tenha existido, exista ou venha existir" (Arendt, 2008, p.16), cujo nascimento é sempre a chegada do novo e da possibilidade de mudança no mundo. Essa pluralidade humana, instaurada pela natalidade, é a condição essencial de toda a vida política (Arendt, 2008).

A política, tal como na pólis grega, representa a liberdade humana e implica relações sem domínio e sem submissão, portanto, interação horizontal entre as pessoas, mediada pelo agir argumentativo - a ação política que é a única atividade humana mediadora, criadora, reveladora e transformadora. Como seres políticos, as pessoas tornam-se inteligíveis entre si e ficam livres do fardo de comandarem ou de serem comandadas.

O espaço de encontro político, na pólis grega, era a esfera pública enquanto o espaço da visibilidade entre as pessoas que se reúnem pela busca do acordo e onde se revela a singularidade, "único lugar em que os homens podiam mostrar quem realmente e inconfundivelmente eram" (Arendt, 2008, p.35). Dessa ação política emerge o poder, relativo à "habilidade humana não apenas para agir, mas 
para agir em concerto" (Arendt, 1994, p.36). A violência, ao contrário, surge da degradação ou instrumentalização da ação política e significa "o agir sem argumentar, sem o discurso ou sem contar com as conseqüências" (Arendt, 1994, p.48). Possui natureza instrumental e se assenta em relações humanas desiguais de mando-obediência (Arendt, 1994).

A esfera pública grega, no entanto, não violava as fronteiras da vida privada, isto porque o suprimento das necessidades da vida no âmbito privado era a condição para que o homem pudesse exercer sua liberdade na esfera pública. O indivíduo passava, então, sua vida transitando entre as duas esferas, na medida em que saía dos limites da sua morada privada, garantidora de um lugar no mundo e de proteção da vida, para adentrar um espaço público em que ele se encontrava com o outro (Arendt, 2008).

O advento da era moderna e "[...] a ascensão da administração caseira, de suas atividades, seus problemas e recursos organizacionais [...] do sombrio interior do lar para a luz da esfera pública" (Arendt, 2008, p.47), alteraram o significado dessas duas esferas da vida humana e representaram a "absorção da família por grupos sociais correspondentes" (Arendt, 2008, p.49), gerando um equacionamento da vida social que "longe de ser uma igualdade entre pares, lembra muito mais a igualdade dos membros da família ante o poder despótico do chefe da casa" (Arendt, 2008, p. 49). A ação da esfera pública é substituída por um comportamento normalizado e o conformismo descarta a possibilidade do novo. Nesse processo de publicização da esfera privada e uniformização da esfera pública, ambas desaparecem, dando lugar ao surgimento de uma nova esfera que a tudo parece consumir e devorar, a esfera social, que integra indivíduos moldados segundo um único interesse - o econômico.

A moderna organização social institui o dinheiro como o seu denominador comum e como o fator definidor da posição social ocupada pelo indivíduo - dominador ou dominado. Neste contexto, surge um mundo determinado pela categoria de meios e fins e regido por uma racionalidade mercadológica e utilitarista que burocratiza a vida do homem. A política perde seu significado interativo e assume caráter de meio regulador; o engessamento da vida humana e a instrumentalização das relações entre as pessoas aniquilam a capacidade de ação dos sujeitos - cria-se o espaço ideal para a violência assumir a posição de mediadora das tensões humanas.

Neste ideário moderno de domínio absoluto reside o mais eficiente mecanismo de controle humano: a sociedade de massas, que homogeneíza comportamentos, interesses, opiniões, sujeitos, numa engrenagem que aniquila a plural singularidade humana, exclui sua ação inovadora e reduz sua capacidade de julgamento, gera o desinteresse do indivíduo pelo mundo comum e por si, enfim, transforma todas as pessoas em meras cópias humanas, reprodutoras de um modelo de sociedade assimétrico, gerador de superfluidade, individualismo, alienação e desvalorização da vida humana. O dilaceramento do tecido humano produz o ambiente favorável ao estabelecimento de interações humanas mudas e regidas pela negação do reconhecimento das pessoas na sua autêntica posição de igualdade.

\section{Metodologia}

Trata-se de estudo qualitativo, realizado no segundo semestre de 2009, cuja metodologia consistiu na realização de trinta grupos focais, com residentes do Município de Ribeirão das Neves, organizados por faixa etária, sexo e regiões administrativas do Município - Justinópolis, Veneza e Centro (Quadro 1). Essa organização objetivou apreender as múltiplas faces do objeto estudado, por meio de vários olhares que conversem entre si e, nesta perspectiva de intersubjetividade, alcancem a objetividade do conhecimento (Habermas, 1996) e evitem a absolutização de um só ponto de vista.

A média de participantes em cada grupo foi de oito pessoas, somando um total de 231 participantes (119 homens e 112 mulheres). Cada grupo durou, em média, oitenta minutos. Por ser uma pesquisa qualitativa, a amostra, neste estudo, não seguiu orientação numérica, ao contrário, foi definida por saturação dos significados coletivos atribuídos ao objeto investigado (Minayo, 1998).

Os participantes foram selecionados aleatoriamente e o recrutamento foi viabilizado com a cooperação de profissionais da rede pública de saúde do município, que propiciou os convites aos 
Quadro 1. Composição dos grupos focais, Ribeirão das Neves-MG, 2009

\begin{tabular}{|c|c|c|c|c|c|c|c|}
\hline Regiões administrativas & Grupos & $\begin{array}{c}10 \text { a } 14 \\
\text { anos }\end{array}$ & $\begin{array}{c}15 \text { a } 19 \\
\text { anos }\end{array}$ & $\begin{array}{c}20 \text { a } 29 \\
\text { anos }\end{array}$ & $\begin{array}{c}30 \text { a } 59 \\
\text { anos }\end{array}$ & $\begin{array}{l}\geq 60 \\
\text { anos }\end{array}$ & Total \\
\hline \multirow[t]{2}{*}{ Justinópolis } & Homens & $\mathrm{HJ}$ & $\mathrm{HJ}$ & $\mathrm{HJ}$ & $\mathrm{HJ}$ & $\mathrm{HJ}$ & 5 \\
\hline & Mulheres & MJ & MJ & MJ & MJ & MJ & 5 \\
\hline \multirow[t]{2}{*}{ Veneza } & Homens & $\mathrm{HV}$ & $\mathrm{HV}$ & $\mathrm{HV}$ & $\mathrm{HV}$ & $\mathrm{HV}$ & 5 \\
\hline & Mulheres & MV & MV & MV & MV & MV & 5 \\
\hline \multirow[t]{2}{*}{ Centro } & Homens & $\mathrm{HC}$ & $\mathrm{HC}$ & $\mathrm{HC}$ & $\mathrm{HC}$ & $\mathrm{HC}$ & 5 \\
\hline & Mulheres & $M C$ & $M C$ & $M C$ & $M C$ & $M C$ & 5 \\
\hline \multicolumn{2}{|l|}{ Total } & 6 & 6 & 6 & 6 & 6 & 30 \\
\hline
\end{tabular}

HJ: Homens de Justinópolis; MJ: Mulheres de Justinópolis; HV: Homens de Veneza; MV: Mulheres de Veneza; HC: Homens do Centro; MC: Mulheres do Centro.

moradores por ocasião de suas visitas domiciliares. Os critérios de inclusão foram: residir no município, ser originário de um dos níveis de vulnerabilidade social (baixo, médio e alto), estar na faixa etária de 10 anos ou mais e ter interesse voluntário em participar. A organização dos grupos por região administrativa garantiu a presença de participantes originários de diferentes condições de vulnerabilidade social (níveis de escolaridade, condições de moradia, renda, acesso aos serviços essenciais e a rede de proteção social etc). Informações obtidas com as equipes de saúde da família do Município permitiram seguir o mesmo critério dentro de cada região.

A organização dos grupos por faixas etárias e sexo, além de captar diferentes olhares, garantiu a homogeneidade de cada grupo (Minayo, 1998) e evitou influências inibitórias da variável gênero e idade no comportamento dos participantes.

Os participantes do estudo ou seus responsáveis assinaram Termo de Consentimento Livre e Informado, contendo informações explicativas sobre a pesquisa. Os grupos foram realizados em escolas de cada região administrativa do município, por serem locais de fácil acesso dos moradores.

A condução dos grupos pelos pesquisadores foi orientada e uniformizada por meio de roteiro prétestado, que continha as questões da temática de interesse, e por instrutivo contendo o passo a passo do trabalho de campo. É importante salientar que todos os 17 integrantes da equipe do trabalho de campo participaram da discussão do tema, da organização e estruturação do trabalho de campo e da construção do roteiro de questões.

O registro dos dados empíricos foi realizado pela gravação das falas de cada grupo. A etapa da análise foi iniciada pelas transcrições das gravações, seguida por uma leitura exaustiva do material transcrito. A seguir, foram definidas categorias analíticas geradas pela articulação dos pressupostos da teoria condutora do estudo com os dados empíricos coletados e, assim, prosseguiu-se com a análise, realizada por um movimento incessante entre as fontes empíricas e teóricas, característico do método hermenêutico-dialético descrito por Minayo (1998). O entrelaçamento entre teoria e prática gerou três categorias de análise: 1) Violência: dominação nas relações humanas, 2) Sociabilidade masculina: modelo centrado na dominação, e 3) Superação da violência.

\section{Resultados e discussão}

A percepção da violência entre os moradores de Ribeirão das Neves mostrou-se abrangente e variada, além de ser referida a episódios sofridos, praticados e/ou assistidos pelos próprios participantes ou chegados ao seu conhecimento por meio de relatos da vizinhança. De um modo geral, a violência para eles é algo que, praticada por um ator, traria danos a outros: "seria qualquer ato, tipo assim, visa prejudicar o próximo, eu vejo desta forma. Aí você pode englobar várias formas, a violência financeira, a violência física, a violência com palavras" (HJ). 


\section{Violência: dominação nas relações humanas}

A concentração estatística da violência entre os homens tem gerado a proposição de que os homens sejam mais violentos do que as mulheres e, de um modo geral, os estudos explicam este fato como sendo resultante de uma naturalização construída socioculturalmente (Carrington et al., 2010; Nascimento et al., 2009; Brasil, 2009a; Alvim, Souza, 2005).

E seria surpreendente encontrar - caso não se adotasse um referencial teórico cujo postulado central é o de que a violência é antes produto da dominação própria das relações desiguais - que os participantes deste estudo consideraram, de uma forma quase que unânime, que tanto homens quanto mulheres são susceptíveis ao envolvimento com a violência, seja na condição de autores ou de vítimas: "eu acho que os dois são violentos, não é a mulher mais que o homem não" (HV), fala que se repete várias vezes, "os dois são violentos da mesma forma" (HC), é "tudo igual porque a mesma capacidade que um tem o outro também tem" (MV). O que muda, segundo eles, são as características da violência em que cada um se envolve "o homem usa mais da força e a mulher usa mais da sabedoria para praticar a violência..." $(\mathrm{HV})$, porém, isso "não quer dizer que a violência seja pior para um ou pior para outro não, ela é idêntica" (HC). E, no encontro da teoria com o mundo empírico, evidencia-se que o potencial de dominação e a disponibilidade de recursos para exercê-lo são os elementos que regem e diferenciam os modos de agir com violência: para Hannah (2008; 1994), a violência é dominação que perpassa as relações humanas, seja entre homens e seja entre mulheres, onde quer que estejam; para os participantes da pesquisa, é a "questão do poderio, pois isso só tinha na cabeça do homem, aí entrou na cabeça também das mulheres" (HC). É óbvio que essa aproximação entre o pensamento de Hannah e o pensamento dos entrevistados (este compatível, é lógico, com o entendimento atual) exige o devido resguardo da premissa, antes mencionada, de que o entendimento de ambos sobre poder é diferente, praticamente contrário, para ela liberdade, para eles dominação. Coerentemente, um estudo de Rosa et al. (2008, p.156) mostra que as relações assimétricas de domínio, na maioria das vezes orientadas por construções de gênero, propiciam cenários de violência por se configurarem como "relações de força expressas enquanto relações de dominação". Outra fala não deixa dúvida quanto a isso, "a mulher quer mandar, entendeu o problema?" (MC), clara intuição - ou quem sabe, receio ou recusa - de que, na história de homens e mulheres, a luta contra a dominação, como já aconteceu em outras searas da experiência humana, possa se transformar, ela própria, em dominação (Horkheimer, Adorno,1975).

Ora, se a violência é dominação que perpassa as relações humanas, então ela é determinada pela forma como se forjam as relações sociais, dependendo dos papéis sociais e atributos que elas engendram, assim como pelas habilidades específicas de cada envolvido. Juntos, estes fatores definem o tipo de violência, o seu espaço de ocorrência, a vítima, o agressor e os instrumentos utilizados.

Não se podem contestar ou ignorar as estatísticas referentes ao envolvimento dos homens com a violência. O conhecimento, porém, do contexto de produção desses números e a compreensão do seu significado trazem nova luz à questão. Segundo os participantes, "o homem é mais violento pela força física" e, além disso, "são eles que mais ficam na rua" (HC). Os números expressariam então as faces visíveis e mensuráveis da violência, referentes a acometimentos físicos graves ou morte, na maioria das vezes, ocorridos no espaço público, e envolveriam, predominantemente, homens, provavelmente em virtude das suas habilidades físicas e de seu papel social que gera maior exposição pública (Schraiber et al., 2005; World Health Organization, 2000). Por outro lado, a face menos visível da violência, que não se explicita tão facilmente ou é de difícil mensuração, por se manifestar de forma simbólica ou velada, foi principalmente atribuída, pelos participantes, às mulheres - "a agressão da mulher pra mim, eu acho que é mais verbal, a mulher não é muito de ... fazer agressão física" (HJ), por isso sua violência é mais "disfarçada" (MC). Ressalta-se que essa face opaca da violência é tão grave como qualquer outra (Caldas, Gessolo, 2008) e, como enfatiza um participante, "tem violência verbal que machuca mais do que um tapa no pé da orelha" (HC). Aliás, muitas vezes, ela desencadeia a violência física (Rosa et al., 2008), fato comentado nos grupos focais: "as mulheres se envolve em violência por questões muitas vezes de uma fofoca ..." (HC), "inclusive se... foi lá e fez uma fofoca de mim, eu vou chegar nela e vou arrumar a maior confusão" (MJ), como no caso; "a minha irmã ... brigou na escola... a menina pegou um negócio da outra, colocou dentro da bolsa dela e falou que foi ela que tinha roubado e não 
era. Minha irmã pegou a cabeça da menina, colocou dentro do vaso e deu descarga" (MV). E também acontece "quando os homens exageram na bebida e as mulheres começam a xingar, ... eles ficam agressivos e começam a bater nelas mesmo" (HV).

Os perfis descritos de envolvimento com a violência não graduam um ou outro sexo como mais ou menos violento, eles mostram que certos tipos de violências são predominantes, mas não exclusivos de homens ou mulheres. Nesse sentido, Schraiber et al. (2005) argumentam que apesar das diferenças nas inserções sociais, não se devem fixar imagens estereotipadas dos homens como eternos agressores e, das mulheres, como eternas vítimas.

Também não se podem excluir as mulheres da prática da violência física, pois ao se considerar o espaço domiciliar, a mãe aparece como a principal agressora contra crianças (Sapi et al., 2009; Brito et al., 2005), mostrando, mais uma vez, a influência das condições assimétricas no exercício da dominação, fato claramente relatado pelos participantes: "A mulher, hoje a mulher é mais violenta através dos pequeninos" ( $M V)$, "a violência das mulheres é com as crianças, é violência doméstica, é dentro de casa" (MV); e tem, entre suas motivações, os problemas conjugais: "Tem mulher também que briga com o marido e quer descontar a raiva nos filhos, bate nos meninos, deixa os meninos mau tratado" (MV), "eu mesma tenho uma irmã que faz isso, ela espanca os filhos dela pra chamar atenção do marido" (MC). E episódios mais graves de violência não são raros no contexto da população estudada, "a gente tem casos na área mesmo, caso recente aí, de uma mãe tentar matar a criança $(\mathrm{MV})$, ou casos em que a mãe "batia com ferro, botava de joelho, amarrava no botijão de gás" (MC). No decorrer da dinâmica do grupo, não faltam testemunhos: "eu acho que já pratiquei, naquela revolta danada, batia nos meninos" (MC).

Muitas vezes, a mãe e a própria sociedade não consideram tais atos como violência, mas como prática educativa e legítima, sem danos à criança (Barbosa, Pegoraro, 2008; Carmo, Harada, 2006), como se verifica na seguinte fala: "Eu dô uma varadinha na perna também, não é só castigo não... eu dô só uma pancadinha nas pernas pra entender que tem que respeitar o papai e a mamãe" (MV). Para Barbosa e Pegoraro (2008), os maus-tratos cometidos pela mãe contra seu filho estão vinculados à posição ocupada por cada membro de uma família e ao papel social da mulher, sendo um desafio à superação da ideia da agressividade restrita ao homem e da imagem materna como ser generoso, incapaz de causar danos aos filhos.

Na relação entre casais, a presente investigação identificou, como outros estudos (Prosman et al., 2011; Caldas, Gessolo, 2008; Krug et al., 2002), o predomínio do homem no papel de agressor e da mulher no papel da vítima - "aqui também tem muito homem batendo em mulher" (HV), "a minha tia... ela casou com um rapaz... e depois que eles casaram ele começou a bater nela..." (MJ). Porém, há outra face, menos frequente e pouco reconhecida, da violência conjugal, em que a mulher aparece como agressora do seu companheiro, "tanto tá tendo violência da mulher contra o homem, quanto do homem contra a mulher" (HC), casos estes de conhecimento deles: "Eu conheço uma mulher que dá varada no homem" (MV), ou vividos por eles: "eu falo que eu posso apanhar, mas ele apanha também. Eu bato nele também, eu bato sem dó... Uma vez assim, que eu tava brigando com o meu marido... eu peguei a tesoura e joguei a tesoura no rosto dele e ele levou vinte pontos... Sempre mais sou eu que agrido ele" (MJ). Casos assim oferecem perigos adicionais, pois além do risco de desencadearem agressão masculina contra a parceira (Rosa et al., 2008), costumam ser - amparados nas teses de autodefesa feminina - aceitos socialmente, sendo raramente denunciados pelos homens, por estarem aprisionados ao ideário da honra (Alvim, Souza, 2005). Fato este enfaticamente expressado nos grupos: "os homens têm vergonha de fazer a denúncia e procurar a polícia" (HJ).

Algumas investigações (Zaleski et al., 2010; Alvim, Souza, 2005; Archer, 2000) sobre violência conjugal identificaram os homens e as mulheres como autores e vítimas dos diversos tipos de violência, e taxas de perpetração e vitimização por violência física mais elevadas foram encontradas entre as mulheres. Melo et al. (2008) identificaram mulheres adolescentes como autoras de agressão física contra homens adolescentes. Rosa et al. (2008) identificaram a agressão física, verbal ou psicológica da companheira como uma das causas desencadeadoras da agressão masculina contra sua parceira.

Surpreendentemente, os grupos focais, tanto de homens como de mulheres, identificam os traços femininos utilizados para subjugar o homem, por exemplo: a facilidade em usar palavras, a arte da 
sedução, posses financeiras ou, mesmo, quando há necessidade do uso da força, a manipulação de outros homens para tal fim: "é a questão do poder... No alto escalão tem empresária aí que pode pagar um pra ceifar o outro, matar e no baixo escalão a mulher pode seduzir um cara aí e falar: mata fulano pra mim ou então dá um pau nele pra mim" (HV). Elementos que também contribuem para a magnitude dos números são as "várias mortes de homens que são encomendas de mulheres" (MV) ou, mesmo, por elas cometidas. Como no caso de "uma mulher que tava fazendo sexo com um cara aí, na hora que ela conseguiu tirar o dinheiro do cara, ela deu uma facada na barriga do cara" (HV). A este respeito, alguns estudos (Krug et al., 2002; Wilson, Daly, 1992) encontraram proporções consideráveis de homicídios masculinos envolvendo a autoria das mulheres.

Portanto, mais do que ser coisa de homem ou de mulher, é a lógica de controle nas relações interpessoais que alimenta o cenário de violência, seja no âmbito da vida pública ou privada, sendo sua autoria e vitimização definidas pela possibilidade de exercício de dominação entre os envolvidos. Rosa et al. (2008) afirmam que, numa organização social desigual, todos são atingidos e tornam-se, ao mesmo tempo, vítimas e autores dos diversos tipos de violência. Enfim, em um mundo assimetricamente organizado, onde todos competem pela posição de dominador, a violência aparece como resultante, sendo consenso entre os participantes que a "violência só vira violência" ( $M V, H V)$. Em outras palavras, a explicação da violência não se esgota nas informações estatísticas, nos estereótipos culturais (Brasil, 2009a; Nascimento et al., 2009) ou nas diferenças biológicas entre os sexos (Carrington et al., 2010; Imura, Silveira, 2010). Restringir-se a esses níveis seria ignorar a sua complexidade e a sua raiz mais profunda.

\section{Sociabilidade masculina: modelo centrado na dominação}

Olhada à luz da teoria arendtiana, a socialização do homem pode ser interpretada na perspectiva da massificação humana, segundo um modelo dominador e de dominação, que se assenta na soberania masculina e na subjugação do outro, contrariando o princípio de igualdade e a condição de liberdade das pessoas. Esta forma de socialização, por sua vez, acaba por reforçar os padrões da moderna dinâmica macrossocial, fundada em relações desiguais. Dessa forma, os homens seriam, então, simultaneamente aprisionados nas condições de agentes e de grandes vítimas de um modelo violento de socialização. Reféns dessas exigências sociais muitos deles perdem a vida ou tiram a vida de outras pessoas na busca de afirmação de um sexo social (Diniz et al., 2003). Segundo esse modelo, o 'ser macho' - atributo pautado na valentia e na soberania do homem, seja sobre a mulher ou sobre outras pessoas - é o principal requisito para afirmação do 'ser homem' (Nascimento et al., 2009; Alvim, Souza, 2005), percepção praticamente unânime dos participantes: "Ser macho é achar que pode tudo...é achar que é o dono da situação..., então eu sou o machão..., por isso eu bato no cê, eu mato ocê" $(\mathrm{HC})$, porque "o homem é quem manda" (MV).

Tudo que simboliza dominação e proporciona uma sensação de coragem, de invulnerabilidade, de aumento da força - como, por exemplo, o álcool ou as armas - dá aos homens a impressão de serem mais homens (Nascimento et al., 2009; Alvim, Souza, 2005), como expressa um participante: "É porque são homens, tipo assim, por causa do motivo que eles tá com revolver, tá com a faca, eles se sente mais homem, aí que acontece as coisas" (HV). Questões que ferem ou ameaçam esses tradicionais atributos masculinos são fatores motivadores do envolvimento dos homens com a violência (Carrington, 2010), como ocorre com a suspeita de traição pela mulher, fantasiosa ou de fato, que muito perturba os homens: "Ah, não aceito traição não" (HV), por isso "tem mulher aqui que apanha pra cachorro..." (HV). Neste cenário, a prática da violência contra a companheira assume um caráter punitivo e expressa a forma de o homem afirmar o domínio sobre a mulher ou demarcar sua propriedade frente aos outros homens (Nascimento et al., 2009; Alvim, Souza, 2005).

Os grupos focais, especificamente os de homens, possibilitaram perceber que o empoderamento da mulher na sociedade moderno-contemporânea tem gerado sofrimento e insegurança aos homens, e isto provavelmente ocorre em decorrência da perda de sua soberania e dos seus espaços de controle (Nascimento et al., 2009; Alvim, Souza, 2005). Nesse novo cenário das relações humanas, os homens estão confusos e sentem-se ameaçados, fato que se reflete diretamente em suas relações no âmbito 
social e da família. Na tentativa de resgatarem sua posição de dominador, demarcarem sua propriedade e de exteriorizarem suas angústias, utilizam a violência, que tem sido o instrumento mais atrativo para se tentar resolver conflitos: "se o homem não fizer nada, ele não vai valer nada e aí vai ser violento" (MC).

Se, como diz Arendt (2008), a posição econômica é definidora da posição social ocupada pelo indivíduo, então, nenhuma surpresa há nas falas que mostram, não sem amargura, a vinculação da condição do homem aos aspectos financeiros:

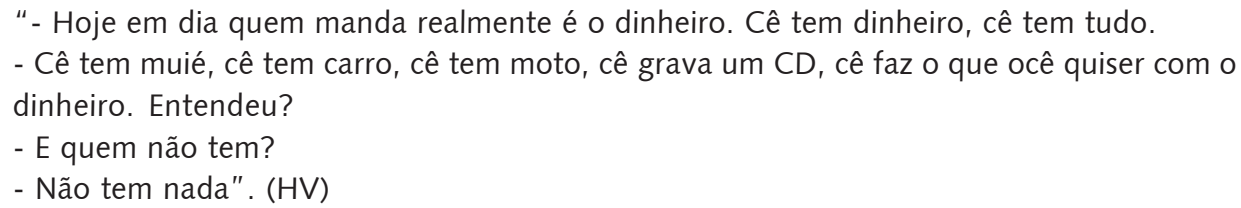

A impossibilidade de exercer o papel de provedor, como no caso do desemprego ou dos baixos salários, aparece, neste estudo e em outros (Krishnan et al., 2010; Rosa et al., 2008), como fator gerador de violência entre casais e de abandono por parte da mulher, denunciando uma relação entre casais muito atrelada ao fator financeiro: o "desemprego afeta muito o casamento" e "gera violência" (HV). Pois quando "o cara ... tá trabaindo fichado, bonitinho, a mulher trata o cara igual um príncipe, igual um rei. Agora quando o cara tá parado, desempregado, a hora mais difícil que a mulher tem que tá do lado do cara... a mulher vai e manda o cara embora, então vira bagunça, vira guerra mesmo, vira violência" $(\mathrm{HV})$. A ideia da parceira é de que o homem tem que "se virar com as despesas de casa" (MV).

Nessa condição, todo obstáculo ao cumprimento das imposições sociais aumenta a vulnerabilidade do homem para o envolvimento com condições violentas, pois na busca de soluções: "Vai traficar, vai roubar... por isso os homens têm mais facilidade de envolver com as drogas, que é uma maneira mais fácil pra conseguir o dinheiro" (HV). Sem contar a adoção de soluções drásticas, como no caso do suicídio (Cleary, 2012): Se "hoje a gente trabalha e temos um salário de dois mil por mês e chega amanhã você é mandado embora ganhando quinhentos reais no mês eu botava uma corda no pescoço e me enforco" (HV).

\section{Superação da violência}

A desvalorização da vida aparece nas falas dos participantes como uma das resultantes mais graves da moderna dinâmica social desumana e, consequentemente, violenta: "hoje em dia também a vida do ser humano não tá valendo nada não" (HV), "as pessoas matam os outros e quase sempre fica por isso" $(\mathrm{HJ})$. O isolamento, resultante do medo e da insegurança, aparece como um dos pilares perpetradores e perpetuadores dessa dinâmica social: "Eu fico lá na minha casa com a porta, com esse calorão, porta, janela, tudo trancado. De medo. Quando eu saio lá fora eu saio rapidinho, faço o que eu tenho que fazer e volto pra dentro. Então quando eu escuto um tiro, nosso Deus!" (MV). Ora, o isolamento das pessoas impede a ação política, como diz Arendt (2008): "sem a ação para por em movimento no mundo o novo começo de que cada homem é capaz por haver nascido, não há nada que seja novo debaixo do sol". Entrelaçada ao isolamento humano tem-se a discriminação, apanágio de um modelo de sociedade massificada, criador de estereótipos sociais ideais e excludentes de quem não os segue: "a maioria da violência é isso também a discriminação... igual eu já fui procurar emprego várias vezes, na hora que fala aonde mora, as pessoas não dá emprego, sabe?" (MV), e "às vezes só porque o cara tá andando de bonezinho, o cara tem uma roupa mais ou menos boa e simples... o pessoal fala: é traficante, é bandido, malandrinho" (HV).

De imediato, este estudo permite reconhecer a degradação do diálogo e a perda dos encontros no espaço público como elementos propulsores da violência, tal como afirma Arendt $(2008,1994)$; e, por consequência, o resgate dessa habilidade é o caminho para a superação da violência (Melo et al., 2007): "feliz do homem que acha que dá pra resolver na conversa e resolve" (HC), "eu acho que as pessoas têm que si respeitar mais, conversar mais", para "chegar num acordo, afinal o acordo serve pra gerar harmonia" (MJ). 
Tal iniciativa implica mudanças amplas das relações sociais e das construções de gênero, cujo início, porém, pode ser aqui e agora, à disposição de cada um, pois é no dia a dia onde se engendra a violência, e que se engendra, também, a possibilidade de sua superação, a partir da relação dialética de singularidade e pluralidade, que faz nascer e renascer incessantemente nossas esperanças de relações humanas mais igualitárias, germinadas na inquebrantável certeza, honrosamente compartilhada com Hannah Arendt $(2008,1994)$, de que "ser homem é uma coisa muito sublime, não é só ser macho não, não, ser macho é muito pouco, qualquer vagabundo é" (HC).

\section{Considerações finais}

Tanto os homens quanto as mulheres foram identificados pelo estudo como sujeitos vulneráveis ao envolvimento com a violência, e as relações desiguais de dominação ditando a forma do envolvimento de cada um. A vulnerabilidade dos homens é agravada por sua socialização, que os condiciona à posição de dominador, institui a violência como um atributo próprio da sua natureza e os aprisiona na condição de vítimas e autores de violência. Essa condição, por sua vez, reforça os padrões da moderna dinâmica macrossocial de dominação. A superação dessa condição, assim como de qualquer relação de dominação, passaria pelo resgate da ação política descrita por Hannah Arendt, ou seja, pelo resgate da palavra viva e da ação vivida, fontes do poder legítimo, que além de preservarem os espaços públicos de revelação entre os sujeitos, tornam os seres humanos não apenas inteligíveis entre si, mas sujeitos livres e autônomos e, portanto, capazes de construir uma nova ordem no mundo. Dessa forma, será possível remodelar masculinidades mais flexíveis, saudáveis e pautadas no estabelecimento de relações mais igualitárias dos homens junto aos seus pares e ao sexo oposto.

Os dados desta investigação problematizam a importante questão de ser a violência um dos principais agravos para a saúde do homem, e revelam, ao buscarem raízes mais profundas do fenômeno, importantes elementos contextuais explicativos dessa estreita relação. Espera-se, com isso, contribuir para o seu melhor entendimento e somar força às inúmeras iniciativas que buscam melhores intervenções com vistas à superação do problema.

É importante destacar a limitação própria da metodologia qualitativa de não permitir a extrapolação dos resultados para outras populações, além da estudada. Por outro lado, o cuidado em organizar os grupos focais por sexo e faixa etária permitiu apreender diversos olhares, evitar absolutizações e produzir conhecimento objetivo sobre o tema.

\section{Colaboradores}

Rejane Aparecida Alves e Elza Machado de Melo realizaram o delineamento da pesquisa, o trabalho de campo, a análise dos dados e a redação do manuscrito. Lauriza Maria Nunes Pinto participou do trabalho de campo e colaborou na redação; e Andréa Maria Silveira e Graziella Lage Oliveira colaboraram na redação do artigo. 


\section{Referências}

ALVES, R.A. As múltiplas e complexas faces da saúde do homem: um estudo da violência em Ribeirão das Neves-MG. 2011. Dissertação (Mestrado) - Faculdade de Medicina, Universidade Federal de Minas Gerais, Belo Horizonte. 2011.

ALVIM, S.F.; SOUZA, L. Violência conjugal em uma perspectiva relacional: homens e mulheres agredidos/agressores. Psicol. Teor. Prat., v.7, n.2, p.171-206, 2005.

ARCHER, J. Sex differences in aggression between heterosexual partners: a metaanalytic review. Psychol. Bull., v.126, n.5, p.651-80, 2000.

ARENDT, H. A condição humana. Trad. Roberto Raposo. 10.ed. Rio de Janeiro: Forense Universitária, 2008

Sobre a violência. Trad. André Duarte. Rio de Janeiro: Relumé-Dumará, 1994.

BARBOSA, P.Z.E.; PEGORARO R.F. Violência doméstica e psicologia hospitalar:

possibilidades de atuação diante da mãe que agride. Saude Soc., v.17, n.3, p.77-89, 2008.

BRASIL. Datasus, 2009. Disponível em: <http://www.datasus.gov.br >. Acesso em: 18 nov. 2011.

Ministério da Saúde. Secretaria de Atenção à Saúde, Departamento de Ações Programáticas estratégicas. Política Nacional de Atenção Integral à Saúde do Homem: princípios e diretrizes. Brasília: Ministério da Saúde, 2009a.

Gabinete do Ministro. Portaria $\mathrm{n}^{\circ} 1.944$, de 27 de agosto de 2009. Institui no âmbito do Sistema Único de Saúde (SUS) a Política Nacional de Atenção Integral à Saúde do Homem. Brasília: MS, 2009b

BRITO, A.M.M. et al. Violência doméstica contra crianças e adolescentes: estudo de um programa de intervenção. Cienc. Saude Colet., v.10, n.1, p.143-9, 2005.

CALDAS, J.M.P.; GESSOLO, K.M. Violencia de género: nuevas realidades y nuevos retos. Saude Soc., v.17, n.3, p.161-70, 2008

CARMO, C.J.; HARADA, M.J.C.S. Violência física como prática educativa. Rev.

Latino-am. Enferm., v.14, n.6, p.17-25, 2006.

CARRINGTON, K. et al. Globalization, frontier masculinities and violence: booze, blokes and brawls. Br. J. Criminol., v.50, n.3, p.393-413, 2010.

CLEARY, A. Suicidal action, emotional expression, and the performance of masculinities. Soc. Sci. Med., v.74, n.4, p.498-505, 2012.

COUTO, M.T. et al. Homens na atenção primária: discutindo (in)visibilidade a partir da perspectiva de gênero. Interface - Comunic., Saude, Educ., v.14, n.33, p.257-70, 2010

DINIZ, N.M.F. et al. Violência conjugal: vivências expressas em discursos masculinos.

Rev. Esc. Enferm. USP, v.37, n.2, p.81-8, 2003.

GOMES, R.; NASCIMENTO, E.F. A produção do conhecimento da saúde pública sobre a relação homem-saúde: uma revisão bibliográfica. Cad. Saude Publica, v.22, n.5, p.901-11, 2006.

HABERMAS, J. Between facts and norms, contributions to a discourse theory of law and democracy. Cambridge: The MIT Press, 1996.

HORKHEIMER, M.; ADORNO, T. Conceito de Iluminismo. São Paulo: Abril Cultural, 1975. (Coleção os Pensadores, v.48).

IMURA, C.P.; SILVEIRA, A.M. Como explicar a violência. In: MELO, E.M. (Org.). Podemos prevenir a violência: teorias e práticas. Brasília: Organização Panamericana de Saúde, 2010. p.25-50. 
INSTITUTO BRASILEIRO DE GEOGRAFIA E ESTATÍSTICA. Disponível em: < http:// www.ibge.gov.br>. Acesso em: 18 nov. 2011.

KRISHNAN, S. et al. Do changes in spousal employment status lead to domestic violence? Insights from a prospective study in Bangalore, India. Soc. Sci. Med., v.70, n.1, p.136-43, 2010. doi: 10.1016/j.socscimed.2009.09.026

KRUG, E.G. et al. World report on violence and health. Geneva: World Health Organization, 2002.

LAURENTI, R. et al. Perfil epidemiológico da morbi-mortalidade masculina. Cienc. Saude Colet., v.10, n.1, p.35-46, 2005.

MELO, E.M. et al. Eles morrem mais do que elas. Por quê? Rev. Med. Minas Gerais, v.18, n.4, p.S12-8, 2008.

A violência rompendo interações: as interações superando a violência.

Rev. Bras. Saude Matern. Infant., v.7, n.1, p.89-98, 2007.

MERYN, S.; JADAD, A. The future of men and their health: are men in danger of extinction? Br. Med. J., v.323, n.7320, p.1013-4, 2001.

MINAYO, M.C.S. O desafio do conhecimento: pesquisa qualitativa em saúde. 5. ed. São Paulo: Hucitec, 1998.

NASCIMENTO, E.F. et al. Violência é coisa de homem? A "naturalização" da violência nas falas de homens jovens. Cienc. Saude Colet., v.14, n.4, p.1151-7, 2009.

PROSMAN, G.J. et al. Prevalence of intimate partner violence among migrant and native women attending general practice and the association between intimate partner violence and depression. Fam. Pract. Int. J., v.28, n.3, p.267-71, 2011.

RIBEIRÃO DAS NEVES. Prefeitura. Superintendência de controle, avaliação e desenvolvimento da qualidade e superintendência de administração, Prefeitura Municipal de Ribeirão das Neves, Minas Gerais. Plano Municipal de Saúde 2008-2011. Rio das Neves: Prefeitura Municipal, 2008.

ROSA, A.G. et al. A violência conjugal contra a mulher a partir da ótica do homem autor de violência. Saude Soc., v.17, n.3, p.152-60, 2008.

SAPI, M.C. et al. Assessment of domestic violence against children and adolescents with enuresis. J. Pediatr., v.85, n.5, p.433-7, 2009.

SCHRAIBER, L. B. et al. Homens e saúde na pauta da Saúde Coletiva. Cienc. Saude Colet., v.10, n.1, p.7-17, 2005.

SMITH, J.A.; ROBERTSON, S. Men's health promotion: a new frontier in Australia and the UK? Health Promot. Int., v.23, n.3, p.283-9, 2008.

TONG, S.F. et al. Profile of men's health in Malaysia: problems and challenges. Asian J. Androl., v.13, n.4, p.526-33, 2011.

UNITED NATIONS. World population ageing 2009. New York: Department of Economic and Social, Affairs Population Division, 2010.

UNITED NATIONS OFFICE ON DRUGS AND CRIME. 2011 global study on homicide: trends, contexts, data. Viena: UNODC, 2011.

WILSON, M.; DALY, M. Who kills whom in spouse killings? On the exceptional sex ratio of spousal homicides in the United States. Criminology, v.30, n.2, p.189-215, 1992.

ZALESKI, M. et al. Violência entre parceiros íntimos e consumo de álcool. Rev. Saude Publica, v.44, n.1, p.53-9, 2010. 
WORLD HEALTH ORGANIZATION. Violence prevention: the evidence. Geneva: WHO, 2010a.

Injuries and violence: the facts. Geneva: WHO, 2010b.

Boys in the picture. Geneva: WHO, 2000.

ALVES, R.A. et al. Hombres, víctimas y perpetradores de la violencia: la corrosión del espacio público y la pérdida de la condición humana. Interface - Comunic., Saude, Educ., v.16, n.43, p.871-83, out./dez. 2012.

Estudio cualitativo realizado en la Ciudad de Ribeirão das Neves, estado de Minas Gerais, Brasil, con el fin de entender la implicación de los hombres con la violencia. Se organizaron 30 grupos de discusión, delimitados por sexo, edad y región administrativa con, un total 231 de participantes. Se utilizó el método hermenéuticodialéctico y, a la luz de la teoría política de Hannah Arendt, la violencia fue interpretada como la dominación que impregna las relaciones humanas. Hombres y mujeres fueron identificados como posibles responsables y víctimas de la violencia, la participación de cada uno de ellos definida sobre la base de las relaciones desiguales que establecen. Los números de la violencia y las explicaciones centradas en las teorías biológicas pueden llevar a la conclusión prematura de que los hombres son más violentos que las mujeres. El marco teórico y la contextura más profundos permiten esclarecer otros aspectos de este problema.

Palabras clave: Salud del hombre. Violencia. Socialización. Masculinidad. 
Ricardo Pozzo, Ocupação Nova Primavera-CIC/Sabará, 2012

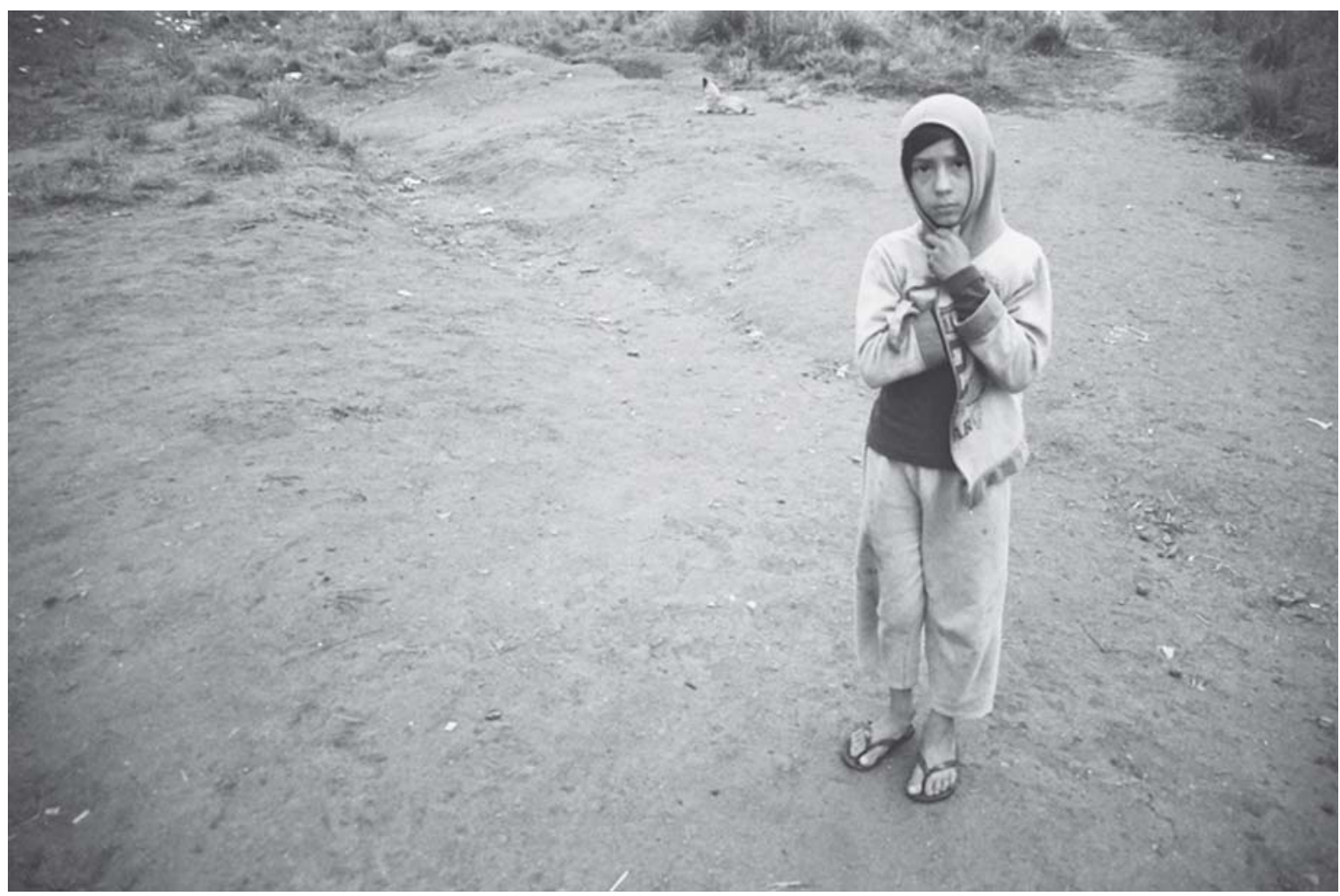

